\title{
Aborto e saúde pública no Brasil: reflexões sob a perspectiva dos direitos humanos
}

\author{
Abortion and public health in Brazil: reflections from the perspective of human rights \\ Karla Ferraz dos Anjos'; Vanessa Cruz Santos²; Raquel Souzas³; Benedito Gonçalves Eugênio4
}

${ }^{1}$ Mestre em Enfermagem e Saúde do Programa de Pós-Graduação em Enfermagem e Saúde pela Universidade Estadual do Sudoeste da Bahia (PPGES/ UESB) - Jequié (BA), Brasil. karla.ferraz@hotmail.com

${ }^{2}$ Mestranda do Programa de PósGraduação em Enfermagem e Saúde, da Universidade Estadual do Sudoeste da Bahia (PPGES/UESB) - Jequié (BA), Brasil. vanessacrus@hotmail.com

${ }^{3}$ Doutora em Saúde Pública pela Universidade de São Paulo (USP) São Paulo (SP), Brasil. Pesquisadora da Universidade de São Paulo - São Paulo (SP), Brasil. Professora Adjunta da Universidade Federal da Bahia (UFBA) Vitória da Conquista (BA), Brasil. raquelasouzas@hotmail.com

${ }^{4}$ Doutor em Educação pela Universidade Estadual de Campinas (UNICAMP) Campinas (SP), Brasil. Professor Adjunto da Universidade Estadual do Sudoeste da Bahia (UESB) - Vitória da Conquista (BA), Brasil.

beneditoeugenio@hotmail.com
RESUMO: O estudo objetivou descrever a relação entre aborto e saúde pública no Brasil, sob a perspectiva dos direitos humanos. Trata-se de uma revisão de literatura realizada na base de dados SciELO. Verificou-se que a busca de mulheres pelos seus direitos perdura por décadas e, mesmo alcançando várias conquistas, como as ocorridas na assistência à saúde da mulher, ainda são necessárias outras mudanças, como, por exemplo, na assistência preventiva da gravidez indesejada e no respeito aos direitos humanos de mulheres que desejam abortar. Conclui-se que, por conta da criminalização do aborto no País, diversas mulheres realizam este procedimento de forma insegura, provocando danos a sua própria saúde, o que se configura em uma violação dos direitos humanos.

PALAVRAS-CHAVE: Saúde da mulher; Aborto; Direitos sexuais e reprodutivos; Autonomia pessoal; Direitos humanos.

ABSTRACT: The study aimed to describe the relation between abortion and public health in Brazil from the perspective of human rights. This is a literature review, held in the SciELO database. It was found that the search of women for their rights endures for decades and, even reaching various achievements, such as those that occurred in women's healthcare, there are still required other changes, such as preventive assistance of unwanted pregnancy and the human rights of women wishing to abort. It is concluded that, because of criminalization of abortion in the country, several women perform it in a unsafely manner, causing damage to their own health, a violation of human rights.

KEYWORDS: Women's health; Abortion; Sexual and reproductive rights; Personal autonomy; Human rights. 


\section{Introdução}

A trajetória das mulheres na busca por seus direitos provém de décadas atrás. Entre esses direitos está o acesso aos serviços e ações de saúde de qualidade, o que não acontece efetivamente no Brasil, mesmo após a implantação de políticas públicas que incluem a saúde sexual e reprodutiva das mulheres.

No Brasil, a saúde da mulher foi inserida nas políticas nacionais de saúde nas primeiras décadas do século XX, sendo, neste período, restrita às demandas referentes à gravidez e ao parto. Os programas materno-infantis, criados nas décadas de 1930, 1950 e 1970, traduziam uma visão limitada sobre a mulher, baseada em sua especificidade biológica e no seu papel social de mãe e doméstica, responsável pela criação, educação e cuidado com a saúde dos filhos e demais membros da família (BRASIL, 2007a).

Historicamente, a posição reservada às mulheres, no que se refere às normas sexuais e reprodutivas, era um dos pontos de maior tensâo no momento da elaboração e da aplicação de leis e políticas. Geralmente, estas leis e políticas estabeleciam mais restriçóes à liberdade sexual e reprodutiva feminina, justificadas como necessárias para a reproduçáo e o desenvolvimento saudável da população (VENTURA, 2009).

Em se tratando dos direitos das mulheres, especificamente os relacionados à saúde sexual e reprodutiva, é importante enfatizar que o planejamento familiar, inserido nas Estratégias de Saúde da Família, precisa realizar açóes direcionadas à saúde integral da mulher, não a restringindo ao seu papel social de procriaçáo, mas também abrangendo a prevenção da gravidez indesejada, que, por conseguinte, pode desencadear o aborto induzido. Para Nader, Blandino e Macie (2007), a principal problemática do aborto induzido está associada à gravidez indesejada, sendo preciso, portanto, ampliar as possibilidades de planejar a gestação, valorizando assim, o Planejamento Familiar.

Um estudo realizado sobre a epidemiologia do aborto em uma população em situação de pobreza na Favela Inajar de Souza, em São Paulo (SP), identificou um elevado número de abortos inseguros entre as mulheres. Na maioria das vezes, as mulheres em situação de pobreza recorrem ao aborto clandestino como forma de "planejamento familiar", como denotam as taxas de gestação. Porém, no grupo estudado, verificou-se também a elevada taxa de complicaçóes pós-aborto revertidas em internações hospitalares (FUSCO; ANDREONI; SILVA, 2008).

Uma das problemáticas referentes ao aborto, que emerge como questão de saúde pública, é a sua forma de realização, que ocorre, na maioria das vezes, de maneira clandestina e insegura, provocando várias implicações biopsicossociais à mulher. Além disso, abortar em condições desfavoráveis à saúde é uma violação dos direitos humanos, principalmente para as mulheres com baixo grau de escolaridade, pobres e negras.

$\mathrm{O}$ ato de abortar de forma insegura pode ser considerado uma injustiça social. Índices de mortalidade decorrentes do aborto, na maioria das vezes, refletem mulheres solteiras ou separadas judicialmente. As desigualdades dos efeitos danosos da clandestinidade e da criminalização do aborto atingem principalmente a parte mais vulnerável da população, de mulheres pobres e negras, com baixa escolaridade; as mais jovens e aquelas com menor acesso à informação. Além disso, quando se trata da razão de mortalidade materna por aborto, em relação às mulheres negras, obtém-se 11,28/100 mil nascidos vivos, ou seja, duas vezes mais do que em relação às mulheres brancas (MARTINS; MENDONÇA, 2005).

Tratando-se da ilegalidade do aborto no Brasil, verifica-se que esta favorece o ganho ilícito de pessoas com manobras abortivas e a sociedade permanece enraizada em ideologias favoráveis à criminalização apenas das mulheres, não analisando quem elas são, o risco de morbidade e mortalidade ao praticar o aborto, a eficácia de programas de planejamento familiar e as iniquidades existentes no contexto social do qual as mesmas fazem parte (SOUZA; DINIZ; COUTO, 2010).

Diante desse contexto, justifica-se a realização do presente estudo, que está subsidiado na discussão do aborto clandestino e/ou inseguro, considerado um problema complexo de saúde pública no Brasil e que, entre seus determinantes, encontra-se a sua criminalização, uma violação dos direitos humanos, sexuais e 
reprodutivos. Isto, principalmente das mulheres mais vulneráveis à prática do abortamento inseguro.

Este estudo tem como objetivo discorrer sobre aborto e saúde pública no Brasil, sob a perspectiva dos direitos humanos.

\section{Material e métodos}

Estudo de revisão de literatura, a princípio, realizado por meio da Biblioteca Virtual de Saúde (BVS), sendo conduzido na base de dados Scientific Electronic Library Online (SciELO). A pesquisa estendeu-se aos arquivos do Ministério da Saúde (Brasil), da organização Católicas pelo Direito de Decidir, do Conselho Federal de Medicina e do Núcleo de Estudos de População e Rede Feminista de Saúde. A busca dos estudos ocorreu a partir dos seguintes descritores: saúde da mulher; aborto; direitos sexuais e reprodutivos; autonomia pessoal: e direitos humanos. $\mathrm{Na}$ articulação das palavras foi adotada a expressão booleana "AND", que permite a inserção de duas ou mais palavras. O período de busca deu-se entre os meses de abril e julho de 2012.
Os critérios utilizados para inclusão do material selecionado foram: disponibilidade on line do texto completo; relação dos artigos com o aborto ilegal; e trabalhos favoráveis e defensivos à descriminalização do aborto, à saúde da mulher, a raça/cor e ano de publicação a partir de 2002. A escolha do período de publicação ocorreu devido ao fato de o Ministério da Saúde (MS) ter elaborado, no referido ano, o Manual de Assistência ao Planejamento Familiar, instrumento que também norteou a discussão da temática. Foram excluídos os artigos que se encontravam duplicados na base de dados, que abordavam apenas o aborto espontâneo e os que não continham, no título, o termo aborto.

A partir da busca na base de dados foram encontrados 133 trabalhos relacionados ao tema. Dentre esses, realizou-se a leitura flutuante de 24 , que resultaram em leitura exaustiva e seleçâo de 14 para a construção do estudo (Tabela 1).

Os artigos analisados abordam questóes relacionadas à legalização do aborto, à mortalidade materna, à magnitude do aborto no Brasil, às implicaçôes do aborto na saúde pública, a aborto e contracepção, à autonomia da mulher, aos direitos humanos e à decisão pela prática do aborto. Os textos de órgãos e organizações

Tabela 1. Apresentação da síntese dos artigos utilizados na revisão de literatura, segundo autor, ano, título, periódico e base de dados. Vitória da Conquista - BA, Brasil, 2013

\begin{tabular}{|l|c|c|c|}
\hline \multicolumn{1}{|c|}{ AUTOR/ANO } & TítULO & $\begin{array}{c}\text { ÁREA DE CONHECIMENTO } \\
\text { PUBLICADA }\end{array}$ & $\begin{array}{c}\text { PERIÓDICOE BASE DE } \\
\text { DADOS }\end{array}$ \\
\hline $\begin{array}{l}\text { CECATTI, J. G. ET AL./ } \\
\mathbf{2 0 1 0}\end{array}$ & $\begin{array}{c}\text { Aborto no Brasil: um enfoque } \\
\text { demográfico }\end{array}$ & Ginecologia e Obstetrícia & $\begin{array}{c}\text { Rev Bras Ginecol Obstet } \\
\text { SciELO }\end{array}$ \\
\hline $\begin{array}{l}\text { DINIZ, D.; MEDEIROS, } \\
\text { M./2010 }\end{array}$ & $\begin{array}{l}\text { Aborto no Brasil: uma pesquisa } \\
\text { domiciliar com técnica de urna }\end{array}$ & Saúde Coletiva & Ciênc Saúde Coletiva \\
\hline $\begin{array}{l}\text { DOMINGOS, S. R. } \\
\text { F.; MERIGHI, M. A. } \\
\text { B./2010 }\end{array}$ & $\begin{array}{c}\text { Oaborto como causa de } \\
\text { mortalidade materna: um pensar } \\
\text { para o cuidado de enfermagem }\end{array}$ & Enfermagem \\
\hline $\begin{array}{l}\text { FREIRE, N./2012 } \\
\text { Aborto seguro: um direito das } \\
\text { mulheres? }\end{array}$ & Ciência e Cultura & SciELO Anna Nery \\
\hline
\end{tabular}




\begin{tabular}{|c|c|c|c|}
\hline AUTOR/ANO & TíTULO & $\begin{array}{c}\text { ÁREA DE CONHECIMENTO } \\
\text { PUBLICADA }\end{array}$ & $\begin{array}{l}\text { PERIÓDICOE } \\
\text { BASE DE DADOS }\end{array}$ \\
\hline $\begin{array}{l}\text { FUSCO, C. L. B.; } \\
\text { ANDREONI, S.; SILVA, } \\
\text { R. S./2008 }\end{array}$ & $\begin{array}{c}\text { Epidemiologia do aborto inseguro } \\
\text { em uma população em situação de } \\
\text { pobreza. Favela Inajar de Souza, } \\
\text { São Paulo }\end{array}$ & Epidemiologia & $\begin{array}{c}\text { Rev Bras Epidemiol } \\
\text { SciELO }\end{array}$ \\
\hline $\begin{array}{l}\text { GESTEIRA, S. M. } \\
\text { A.; DINIZ, N. M. F.; } \\
\text { OLIVEIRA, E. M./2008 }\end{array}$ & $\begin{array}{l}\text { Assistência à mulher em processo de } \\
\text { abortamento provocado: discurso } \\
\text { de profissionais de enfermagem }\end{array}$ & Enfermagem & $\begin{array}{l}\text { Acta Paul Enferm } \\
\text { SciELO }\end{array}$ \\
\hline GOLLOP, T. R./2009 & $\begin{array}{c}\text { Por que despenalizar } \\
\text { o aborto? }\end{array}$ & Ciência e Cultura & $\begin{array}{l}\text { Cienc Cult } \\
\text { SciELO }\end{array}$ \\
\hline $\begin{array}{l}\text { MENEZES, G.; } \\
\text { AQUINO, E. M. L/2009 }\end{array}$ & $\begin{array}{c}\text { Pesquisa sobre o aborto no Brasil: } \\
\text { avanços e desafios para o campo } \\
\text { da saúde coletiva }\end{array}$ & & $\begin{array}{l}\text { Cad Saúde Pública } \\
\text { SciELO }\end{array}$ \\
\hline $\begin{array}{l}\text { NADER, P. R. A; } \\
\text { BLANDINO, V. R.P; } \\
\text { MACIE, E. L. N./2007 }\end{array}$ & $\begin{array}{c}\text { Características de abortamentos } \\
\text { atendidos em uma maternidade } \\
\text { pública do Município } \\
\text { da Serra-ES }\end{array}$ & Epidemiologia & $\begin{array}{c}\text { Rev Bras Epidemiol } \\
\text { SciELO }\end{array}$ \\
\hline PEREIRA, I. G./2009 & $\begin{array}{l}\text { Casuística de abortos legais } \\
\text { realizados no hospital do } \\
\text { Jabaquara entre } 1989 \text { e } 2007\end{array}$ & Saúde e Sociedade & $\begin{array}{l}\text { Saúde Soc } \\
\text { SciELO }\end{array}$ \\
\hline $\begin{array}{l}\text { PEREIRA, V. N. ET } \\
A L . / 2012\end{array}$ & $\begin{array}{l}\text { Abortamento induzido: vivência de } \\
\text { mulheres baianas }\end{array}$ & Saúde e Sociedade & $\begin{array}{l}\text { Saúde Soc } \\
\text { SciELO }\end{array}$ \\
\hline SCAVONE, L./2008 & Políticas feministas do aborto & Estudos Feministas & $\begin{array}{l}\text { Rev Estud Fem } \\
\text { SciELO }\end{array}$ \\
\hline $\begin{array}{l}\text { SOUZA, Z. C. S. N.ET } \\
A L . / 2010\end{array}$ & $\begin{array}{c}\text { Trajetória de mulheres em situação } \\
\text { de aborto provocado no discurso } \\
\text { sobre clandestinidade }\end{array}$ & Enfermagem & $\begin{array}{l}\text { Acta Paul Enferm } \\
\text { SciELO }\end{array}$ \\
\hline $\begin{array}{l}\text { TEMPORÃO, J. } \\
\text { G./2012 }\end{array}$ & $\begin{array}{l}\text { Direitos sexuais e reprodutivos das } \\
\text { mulheres no Brasil: conquistas } \\
\text { recentes e desafios prementes. }\end{array}$ & Ciência e Cultura & $\begin{array}{l}\text { Cienc Cult } \\
\text { SciELO }\end{array}$ \\
\hline
\end{tabular}

governamentais e não governamentais resultaram em leitura flutuante e seleção de 14 deles para análise. Além disso, fez-se necessária a inclusão de um livro para contextualizar a discussão.

Para a revisão, os artigos foram lidos na íntegra, filtrados e analisados conforme o objetivo proposto e a relevância científica e social dos mesmos. Em seguida, houve a organização e a codificação do material, que seguiu o tratamento dos resultados, com a categorização dos dados, que foi produzida em cinco categorias, a saber: 1) Saúde da mulher com ênfase no Planejamento Familiar; 2) Aborto e saúde pública no Brasil; 3) Aborto 
e a legalização; 4) Implicaçóes do aborto clandestino e/ ou inseguro; e 5) Autonomia pessoal, direitos sexuais e reprodutivos como expressão dos direitos humanos.

\section{Resultados e discussão}

\section{SAÚDE DA MULHER COM ÊNFASE NO PLANEJAMEN- TO FAMILIAR}

No Brasil, nos anos 1980, a ideia de um conjunto de direitos sexuais e reprodutivos também foi introduzida em reivindicações feministas. No campo da saúde, um dos aspectos marcantes da mobilização de feministas e sanitaristas foi a formulação do Programa de Atenção Integral à Saúde da Mulher (PAISM), aprovado pelo Governo Federal em 1983. Essa proposta rompia com a preocupação limitada da saúde materno-infantil sob a perspectiva do nascituro e da família, e agregava açóes direcionadas para além do ciclo gravídico-puerperal, introduzindo assim, um plano de assistência integral à mulher em todas as fases de sua vida, abarcando, inclusive, as questóes relacionadas ao exercício da sexualidade e da autonomia reprodutiva feminina (BRASIL, 2011).

De acordo com Rocha e Barbosa (2009), no transcorrer dos anos, a visão restrita que se tinha sobre a mulher como um ser submisso foi se transformando. A mulher era predestinada a dar à luz, conceber, mesmo sem almejar, não encontrando alternativas para a contracepção, que era moralmente condenada, até certo tempo, mesmo quando esta era casada. Ao se referir à contracepção, particularmente entre as mulheres mais jovens, há déficit de informação sobre os métodos, que, em várias circunstâncias, são utilizados de maneira irregular ou incorreta, expondo-as ao risco de gravidez.

Conforme o proposto pelo Ministério da Saúde, Brasil (2002), foi aprovada pelo Congresso Nacional e sancionada pela Presidência da República a Lei $\mathrm{n}^{\circ}$ 9.263, de 12 de janeiro de 1996, que regulamenta o Planejamento Familiar. Esta lei estabelece que as instâncias gestoras do Sistema Único de Saúde (SUS) têm a obrigatoriedade de garantir à mulher, ao homem ou ao casal, na rede de serviços, assistência à concepção e à contracepção como parte integrante das demais açóes que fazem parte da assistência integral à saúde.

O governo brasileiro, no final de 2007, lançou o Programa Especial de Planejamento Familiar, buscando contornar a problemática relacionada ao aborto, e foi apoiado por um grupo de feministas, que aproveitou o momento para manifestar os princípios feministas do estado laico, dos direitos reprodutivos, da questão do aborto inseguro e a afirmação do projeto de descriminalização (SCAVONE, 2008).

Neste sentido, o Planejamento Familiar, inserido na atenção primária à saúde, precisa ser subsidiado não apenas na reprodução de informações, mas também na criação de espaços de diálogo para que tanto as mulheres quanto, principalmente, os homens possam ser protagonistas e estar envolvidos neste processo e por ele se responsabilizem, participando das decisóes pelo método contraceptivo e dividindo com as mulheres o direito a uma vida reprodutiva que seja guiada pela escolha consciente (NADER; BLANDINO; MACIE, 2007).

$\mathrm{Na}$ rede de atenção do SUS são imprescindíveis: a implementação de açóes que garantam às mulheres informações e o acesso aos métodos contraceptivos, incluindo também a contracepção de emergência, inserida na perspectiva da integralidade da assistência à saúde, como preconiza o PAISM há duas décadas (MENEZES; AQUINO, 2009).

A anticoncepção de emergência, conhecida como pílula do dia seguinte, é outro recurso disponibilizado no âmbito do SUS. Ela é utilizada com o objetivo de prevenir a gravidez indesejada em situaçóes excepcionais, não devendo ser utilizada rotineiramente, em substituição a outros métodos anticoncepcionais. Essa pílula é fornecida desde 2003 aos municípios que possuem população igual ou superior a 50 mil habitantes (TEMPORÃO, 2012).

Acredita-se que as condiçóes socioeconômicas desfavoráveis podem se relacionar com dificuldades para o acesso a informaçóes e aos métodos adequados para se prevenir uma gravidez indesejada, e o abortamento induzido funcionaria como um método de planejamento familiar para mulheres mais carentes, o que é preocupante, pois provavelmente seria realizado de 
maneira insegura, contribuindo para a morbimortalidade materna (CECATTI et al., 2010).

Devido às desigualdades em saúde existentes no Brasil, nas relaçóes de gênero/raça-etnia, e à injustiça social no Brasil, principalmente em se tratando das mulheres negras, criou-se a Política Nacional de Saúde Integral da População Negra e a PAISM. Historicamente, à população negra foram impostas a subalternização à pobreza e condiçóes mais precárias de vida, o que exigiu políticas específicas para, ao menos, reduzir as desigualdades no País (BRASIL, 2007b). Entre estas desigualdades estão as relacionadas aos direitos sexuais e reprodutivos, uma vez que são as mulheres negras (pardas e pretas) as maiores vítimas de gravidez indesejada e, consequentemente, as que realizam maior número de aborto clandestino e/ou inseguro.

\section{ABORTO E SAÚDE PÚBLICA NO BRASIL}

Segundo o Ministério da Saúde, o aborto é a interrupção da gravidez até a $20^{\mathrm{a}}$ ou $22^{\mathrm{a}}$ semana, com o produto da concepção pesando menos de $500 \mathrm{~g}$, sendo este eliminado no processo de abortamento. As causas de abortamento são várias, entretanto, na maioria das vezes, permanecem indeterminadas e inúmeras gestações são interrompidas por decisão própria da mulher (BRASIL, 2010).

Tratando-se da caracterização do aborto no Brasil, verifica-se predominância de mulheres entre 20 e 29 anos, em uniâo estável, com até oito 8 de estudo, trabalhadoras, com pelo menos 1 filho e usuárias de métodos contraceptivos. Estima-se que 1.054.242 abortos foram induzidos em 2005. A fonte de dados para esse cálculo foram as internaçóes por abortamento registradas no Serviço de Informações Hospitalares do SUS. A maior parte dos casos aconteceu no Nordeste e no Sudeste do País, com taxa anual de aborto induzido de 2,07 por 100 mulheres entre 15 e 49 anos (BRASL, 2009).

Estudo realizado por Cecatti et al. (2010), para avaliar a prevalência referida de abortamento espontâneo e induzido em uma amostra de mulheres brasileiras entrevistadas na Pesquisa Nacional sobre Demografia e Saúde (PNDS), de 1996, demonstra que as mulheres que informaram ter realizado aborto espontâneo ou induzido apresentaram características sociodemográficas semelhantes quanto a idade e número de nascidos vivos. Entretanto, as mulheres que referiram ter tido ao menos um aborto induzido geralmente não eram de cor/raça branca (parda e preta), residiam em áreas urbanas, principalmente no Rio de Janeiro, e estavam trabalhando na época da entrevista. A menor escolaridade e a declaração de cor/raça não branca estiveram indiretamente associadas à pobreza e, consequentemente, a um maior risco para o aborto induzido de maneira insegura e com maior risco de morte.

De acordo o Ministério da Saúde, Brasil (2010), o aborto no Brasil acontece em cerca de $10 \%$ das gestaçôes. Entre eles, a maior parte é provocada das mais diferentes maneiras. O abortamento no País resulta de necessidades não satisfeitas de planejamento reprodutivo, envolvendo déficit de informaçóes sobre a anticoncepção, dificuldades de acesso aos métodos, falhas no seu uso, uso irregular ou inadequado e/ou ausência de acompanhamento pelos serviços de saúde.

O estudo de Diniz e Medeiros (2010) chamado "Aborto no Brasil: uma pesquisa domiciliar com técnica de urna" apresenta os primeiros resultados da Pesquisa Nacional sobre Aborto (PNA), levantamento realizado em domicílios de todo o Brasil urbano. As evidências indicaram que o aborto náo era realizado somente para postergar o princípio da vida reprodutiva ou evitar filhos em idades avançadas, pois se notou que cerca de $60 \%$ das mulheres fizeram seu último, ou único aborto, no centro do período reprodutivo (18 e 29 anos). Entre as mulheres que abortaram, 23\% tinham até o $4^{\circ}$ ano do ensino fundamental e $12 \%$, o ensino médio completo.

No Brasil há déficit de estudos epidemiológicos sobre abortamento inseguro, clandestino, especialmente quanto se trata de populaçóes vulneráveis, de renda muito baixa, nas quais existe um peso maior do aborto sobre as taxas de morbidade e mortalidade materna (FUSCO; ANDREONI; SILVA, 2008).

Enfrentar o fenômeno do aborto como uma questão de saúde pública significa entendê-lo como uma questão de cuidados em saúde e não como um ato de infração moral de mulheres consideradas levianas. E, para essa redefinição política, existem algumas 
tendências que se mantêm nos estudos à beira do leito com mulheres que abortaram. O conveniente é que essa descrição não representa apenas as mulheres que abortam, mas as mulheres brasileiras. Neste sentido, compreender o aborto como uma questão de saúde pública em um Estado laico e plural representa um novo caminho de argumentaçóes, no qual o campo da saúde pública no Brasil suscita complexas e relevantes evidências para o debate (DINIZ, 2007).

O aborto, considerado um grave problema de saúde pública, precisa ser enfrentado na perspectiva dos direitos sexuais e reprodutivos. É forçoso reconhecer que penalizar as mulheres que recorrem à prática do aborto com a cadeia, como determina o Código Penal anacrônico, de 1940, é absurdo, além de irreal, uma vez que não se tem filhos por força de lei, tê-los é um projeto afetivo e de responsabilidade de homens e mulheres. Criminalizar o aborto significa penalizar as mulheres, principalmente, as de classes sociais menos favorecidas, que são as que necessitam solucionar sua gestação indesejada, muitas vezes, de maneira insegura (GOLLOP, 2009).

\section{ABORTO E A LEGALIZAÇÃO}

Em países como o Brasil, onde o aborto é criminalizado na maioria das situaçôes, há uma perversidade para com as mulheres, especialmente, às de classe social menos favorecida. Neste contexto, verifica-se que o caráter de ilegalidade do aborto favorece a sua realização de maneira clandestina, e isso é sentido na ausência de serviços e na má qualidade da assistência. Por esse motivo, a quantidade elevada de abortos induzidos no País pode ser constatada (GESTEIRA; DINIZ, OLIVEIRA, 2008).

O Hospital Municipal Arthur Ribeiro de Saboya, localizado em Jabaquara, na Zona Sul da cidade de São Paulo (SP), foi o pioneiro na implantação de programas de atenção à violência sexual contra mulheres e à realizaçáo de abortos previstos em lei, desde 1989. São atendidos os casos previstos no Código Penal Brasileiro (CPB), no Artigo 128, em que "não se pune o aborto praticado por médico quando: não houver outro meio de salvar a vida da gestante; se a gravidez resulta de estupro e o aborto for precedido do consentimento da gestante e quando menor ou incapaz, de seu representante legal". Nos últimos anos incorporou-se o abortamento por malformação fetal grave e incompatibilidade com a vida extrauterina, sendo necessária a autorização judicial (PEREIRA, 2009).

Desde o início do funcionamento do Hospital Artur Saboya de Medeiros, foram fundados cerca de 55 outros serviços no SUS, geralmente localizados em grandes cidades, na maioria, capitais de estados. É evidente que essa rede é insuficiente para um país das dimensões do Brasil. Existe, entretanto, empenho do Ministério da Saúde para ampliar essa rede e capacitar equipes de saúde (GOLLOP, 2009).

No que se refere à legislação e ao aborto no Brasil, em 2012, com a decisão do Supremo Tribunal Federal, mulheres com fetos anencefálicos obtiveram o direito de abortar, o que antes somente era possível a partir da autorização judicial. Entende-se que, nesta situação, não ocorre a formação do cérebro no feto e que esse procedimento não é criminoso perante a justiça, garantindo assim que mulheres possam interromper a gestação desses fetos (KLASING, 2012).

Mesmo diante das severas restriçóes legais do Brasil, o aborto é realizado por diversas mulheres, isto devido ao fato de parte delas compartilharem da mesma situação de ilegalidade da intervenção. Quando a mulher recorre ao aborto inseguro, fica exposta ao risco dos agravos a sua saúde e até à morte. Além disso, enfrenta também o sofrimento moral decorrente de um processo judicial que pode levar a sua condenação (FREIRE, 2012). Neste contexto, a legalidade do abortamento seguro poderá salvar vidas e possibilitar que mulheres não adoeçam e não fiquem sequeladas, além de reduzir gastos com a saúde pública (MARTINS; MENDONÇA, 2005).

Mesmo depois de passada mais de uma década das Conferências Internacionais do Cairo e de Pequim (Beijing), no Brasil e na maior parte da América Latina, o aborto clandestino e inseguro é considerado um grave problema de saúde pública, e sua solução é um desafio a exigir medidas urgentes que passam, fatalmente, pelo processo de descriminalização do mesmo (FUSCO; ANDREONI; SILVA, 2008). 
Apesar de o aborto poder ser utilizado erroneamente como prática contraceptiva por questôes sociais inerentes ao sistema vigente no Brasil, em Cuba, a partir da legalização do aborto em 1965 (configurada no novo Código Penal de 1987), sua prática segura mantém a mortalidade materna em níveis reduzidos quando comparados aos de outros países latino-americanos. Ou seja, legalizar o aborto, realizando-o em adequadas condições sanitárias e por profissional capacitado, possibilitou ampla redução da morte materna. $\mathrm{O}$ aborto legal e seguro, tal como em Cuba, transformaria a realidade brasileira e beneficiaria as mulheres (FUSCO; ANDREONI; SILVA, 2008).

Expressando o desejo da maioria dos participantes de um congresso interno, em março de 2013, o Conselho Federal de Medicina apontou a necessidade da reforma do Código Penal brasileiro, que ainda aguarda votação, com vistas a afastar a ilicitude da interrupção da gravidez quando resultante da vontade da gestante, até a $12^{a}$ semana de gestação. Essa reforma está fundamentada sob a perspectiva ética que considera a autonomia da mulher nos aspectos sociais, jurídicos, epidemiológicos e de saúde pública (CONSELHO FEDERAL DE MEDICINA, 2013).

O Ministério da Saúde, ao se pronunciar sobre "o aborto e saúde pública no Brasil: 20 anos”, descreve que a criminalização do aborto propicia implicações negativas à saúde das mulheres, pouco coíbe a prática, além do que perpetua a desigualdade social. O risco imposto pela ilegalidade do aborto é, em sua maioria, vivido pelas mulheres pobres e pelas que não têm acesso aos recursos médicos para o aborto seguro (BRASL, 2009).

\section{IMPLICAÇÕES DO ABORTO CLANDESTINO E/OU INSEGURO}

$\mathrm{O}$ aborto realizado de maneira insegura, em contextos de ilegalidade, tal qual a situação brasileira, resulta em sérias consequências para a sociedade, pois compromete a saúde da mulher, com elevada morbimortalidade. Além disso, sobrecarrega o sistema de saúde, implica em custos, diminui a produtividade, traz inúmeras repercussóes familiares e estigmatiza a mulher (SEDGH et al., 2007).
As desigualdades regionais e sociais tornam-se bastante evidentes quando se observa as distribuições dos riscos de mortalidade materna em consequência de complicaçóes decorrente do aborto. $\mathrm{Na}$ região Norte, o risco de mortalidade materna em consequência de gravidez que termina em aborto é 1,6 vezes maior do que na região Sudeste. Esse risco para mulheres negras, analfabetas ou semianalfabetas é 2,5 vezes maior do que para mulheres brancas. Nessas primeiras, também a mortalidade materna em consequência de aborto é 5,5 vezes maior do que na categoria de mulheres com 12 ou mais anos de escolaridade (GOLLOP, 2009).

O aborto é uma das principais causas de morte materna no mundo, e sua maior incidência acontece em países em desenvolvimento. Estima-se que no Brasil ocorram mais de um milhão de abortamentos ao ano. Vulnerabilidades, desigualdades de gênero e de acesso à educação, além das múltiplas dimensões da pobreza, como o déficit de recursos econômicos e a dificuldade de acesso à informação e direitos humanos fazem com que o aborto clandestino e/ou inseguro atinja, especialmente, as mulheres pobres e marginalizadas (BRASIL, 2010). Nesta perspectiva, a prevenção da mortalidade materna por aborto depende da existência de serviços de saúde estruturados nos vários níveis de assistência, para garantir atendimento às mulheres (DOMINGOS; MERIGHI, 2010).

Conforme Diniz e Medeiros (2010), os níveis de hospitalização pós-aborto no Brasil são elevados. Em média, $50 \%$ das mulheres que realizaram aborto e recorreram ao sistema de saúde foram internadas devido a complicações. Parte significativa dessas internaçóes poderia ter sido evitada se o aborto não fosse tratado como atividade clandestina e o acesso aos medicamentos seguros fosse garantido.

$\mathrm{O}$ aborto pode implicar em sequelas à saúde física, mental e reprodutiva da mulher. Dentre as complicaçôes físicas imediatas estão as hemorragias, infecções, perfuraçóes de órgãos e infertilidade, que se somam aos transtornos subjetivos, ao se vivenciar o ônus de uma escolha inegavelmente difícil em um contexto de culpabilização e penalização do aborto (BRASIL, 2010).

Estudo realizado com mulheres baianas sobre aborto induzido evidencia como as mulheres vivenciam 
este tipo de aborto, revelando um processo amplamente doloroso, desde o momento em que descobre a gestação, perpassando pela complexa decisão de interrompê-la. Quando não são apoiadas, essas mulheres perpetuam essa dor com angústia e culpa, o que pode levar à depressão. Apesar dos vários avanços nas discussóes e estudos sobre o aborto induzido, é preciso ampliar as reflexóes sobre essa temática a fim de melhorar a atenção à saúde das mulheres que decidem pelo aborto (PEREIRA et al., 2012).

\section{AUTONOMIA PESSOAL, DIREITOS SEXUAIS E REPRODUTIVOS COMO EXPRESSÃO DOS DIREITOS HUMANOS}

Em meados da década de 1970, o feminismo brasileiro já tinha uma posição política sobre o aborto baseada no princípio do direito individual, que remete a um dos fundamentos do feminismo contemporâneo, a saber: o princípio democrático liberal do direito aplicado ao corpo - direito baseado nas ideias de autonomia e liberdade do liberalismo, expresso na máxima feminista "nosso corpo nos pertence", que se difundiu internacionalmente a partir dos países centrais e marcou as lutas feministas relacionadas à sexualidade, à contracepção e ao aborto. A apropriaçáo do corpo também significava, para as mulheres, a possibilidade da livre escolha da maternidade (SCAVONE, 2008).

$\mathrm{Na}$ Conferência Internacional sobre População e Desenvolvimento realizada em 1994, no Cairo, 184 Estados reconheceram os direitos reprodutivos como direitos humanos e reforçaram o exercício dos direitos sexuais reconhecidos em 1995, na IV Conferência Mundial da Mulher, em Beijing. Os direitos sexuais e reprodutivos, além de serem reconhecidos, a partir de entâo, passaram a ser discutidos sob a perspectiva dos direitos humanos, pressupondo o respeito à liberdade $\mathrm{e}$ à autodeterminação, sem coerção ou violência, e o dever dos Estados-parte (Brasil incluído) de garantirem condiçôes sólidas para o exercício desses direitos por meio de leis e políticas públicas (GOLLOP, 2009).

Como parte integral dos direitos humanos, as recomendaçóes do documento provindo da IV Conferência
Mundial da Mulher, em Beijing, estão direcionadas a sensibilizar a mulher sobre si mesma e o contexto onde vive, para que possa exercer sua autonomia ancorada pelo princípio de justiça e dos direitos humanos, para a promoção do desenvolvimento sustentável e igualitário em todas as nações (HESSINI; SMITH, 2005).

Os direitos reprodutivos estão integrados aos direitos humanos e o direito da mulher de decidir sobre o próprio corpo precisa ser aceito e respeitado. Destarte, uma vez que o Estado nega proteção aos direitos reprodutivos, incluindo-se também o acesso ao aborto seguro, contribui para que as repercussóes sobre a saúde mental feminina e os impactos da morbimortalidade por aborto sejam ampliados (MARTINS; MENDONÇA, 2005).

Para Kottow (2005), a partir da abordagem bioética, é importante refletir sobre se a maternidade é realmente um ato de escolha da mulher ou uma imposição social, tomada como "natural". Ao reconhecer o princípio da vida humana por aceitação e compromisso, na visão relacional, esta é considerada uma atitude moralmente louvável e superior às escolhas da mulher e a acolhida passiva da gestação é vista como um fato consumado e irreversível.

Nos debates sobre aborto induzido, os estágios da gestação e do desenvolvimento fetal são determinantes, pois algumas linhas que defendem a descriminalização partem do princípio de que o aborto é um direito da mulher. Segundo essa teoria, é uma prerrogativa da mulher usar o próprio corpo. Além desta, existe a explicação biológica da vida fetal. Conforme esta linha de discussão, se os estímulos nervosos, decorrentes da formação do tubo neural, acontecem em torno do terceiro mês (12 semanas), a interrupção da gestação até esse momento não traria sofrimento para o feto (SOUZA et al., 2010).

A criminalização do aborto viola os direitos das mulheres a sua autodeterminação reprodutiva, violando assim seus direitos humanos (SYDOW et al., 2011). As mulheres precisam ter o direito de decidir se querem ou não interromper a gestação. Trata-se de uma complexa e delicada decisão, mesmo para quem tem acesso ao aborto seguro. Ao retratar a prática do aborto, é preciso 
considerar que várias mulheres engravidam sem planejar (ALMEIDA, 2012).

O ser humano precisa ter livre-arbítrio, e isto se aplica à decisão da mulher frente às questóes relacionadas ao aborto, pois cada indivíduo tem direitos e deveres para com o Estado, que, em vez de punir e incriminar, deveria apoiar e ajudar. Além disso, a política de planejamento familiar não funciona com qualidade no Brasil, logo, o Estado não pode cobrar da mulher algo que ele não executa em conformidade como os direitos dessa mesma mulher (SYDOW et al., 2011). Sendo assim, a revisão da legislação brasileira frente ao aborto pode favorecer a implementação de ações que assegurem maior autonomia das mulheres nas questóes reprodutivas (MENEZES; AQUINO, 2009).

As mulheres necessitam ter autonomia sobre sua sexualidade e seu corpo, além do que o debate do aborto deveria ser guiado pelo bem comum da sociedade. Sob o ponto de vista da saúde pública, a situação contemporânea de mortes de mulheres em plena capacidade reprodutiva é insustentável. Nessa direção, e em coerência com as bases democráticas do Brasil, torna-se essencial a instalação de amplo debate nacional sobre a temática, que culminaria em manifestação da sociedade em voto plebiscitário. A descriminalização do aborto seria uma medida de elevado impacto para a reversão dos atuais indicadores de morbidade e mortalidade feminina (TEMPORÃO, 2012).

\section{Considerações finais}

A partir dos resultados deste estudo, verificou-se que a busca de mulheres por direitos, entre eles, o acesso às açóes e serviços de saúde, perdura por décadas. Vários grupos feministas, a partir de suas lutas e ideologias, conseguiram amenizar a forma como a mulher é vista na sociedade, principalmente, quando se trata dos direitos sexuais e reprodutivos. Entretanto, várias mudanças ainda precisam acontecer, como a redução dos índices elevados de aborto no Brasil e, consequentemente, da mortalidade materna, que, por conta da assistência à saúde sexual e reprodutiva que é ofertada de maneira deficiente no país (como o planejamento familiar), faz com que mulheres acabem por engravidar de forma indesejada e várias decidam pela prática do aborto.

Mesmo diante das mudanças favoráveis ocorridas à saúde da mulher no Brasil, quando se trata do aborto, especificamente o induzido, nota-se que as mulheres não têm direito sobre o próprio corpo, haja vista que por ser ilegal no Brasil na maioria das situaçôes, diversas recorrem a práticas clandestinas e/ou inseguras, colocando a própria vida em risco. Isto é uma violação dos direitos humanos e um problema de saúde pública, tanto por sua magnitude, como por desencadear inúmeras consequências biopsicossociais às mulheres que recorrem a esta forma de abortamento.

\section{Referências}

ALMEIDA, H. B. Aborto: o grande tabu no Brasil. Católicas pelo Direito de Decidir. 2012. Disponível em: <http://www.catolicas.org. br/noticias/conteudo.asp?cod=3409>. Acesso em: 28 mar 2012.

BRASIL. Ministério da Saúde. Assistência em Planejamento Familiar: Manual Técnico. Secretaria de Políticas de Saúde. Área Técnica de Saúde da Mulher. 4. ed. 2002. Disponível em: <http://bvsms.saude.gov.br/bvs/publicacoes/0102assistencia1.pdf>. Acesso em: 16 abr 2012.

Política Nacional de Atenção Integral à Saúde da Mulher: princípios e diretrizes. Secretaria Especial de Políticas de Promoção da Igualdade Racial. 2007a. Disponível em: <http://conselho. saude.gov.br/ultimas_noticias/2007/politica_mulher.pdf>. Acesso em: 2 mar. 2012.

Política Nacional de Saúde Integral da População Negra. Secretaria de Gestão Estratégica e Participativa. 2007b. Disponível em: <http://conselho.saude.gov.br/ultimas_noticias/2007/politica_mulher.pdf>. Acesso em: 28 mar. 2012

Secretaria de Ciência, Tecnologia e Insumos Estratégicos. Departamento de Ciência e Tecnologia. Aborto e Saúde Pública 20 anos. 2009. Brasília: Ministério da Saúde, 2009. 428 p. (Série B. Textos Básicos de Saúde). Atenção Humanizada ao Abortamento: Norma Técnica. 
Secretaria de Atenção à Saúde. Departamento de Ações Programáticas Estratégicas. 2. ed. Brasília. 2010. Disponível em: <http:// portal.saude.gov.br/portal/arquivos/pdf/atencao_humanizada. pdf>. Acesso em: 09 mai 2012.

. O progresso das mulheres no Brasil 2003 - 2010. Organização: Leila Linhares Barsted e Jacqueline Pitanguy. Brasília: ONU Mulheres, 2011.

CECATTI, J. G. et al. Aborto no Brasil: um enfoque demográfico. Revista Brasileira de Ginecologia e Obstetrícia, Rio de Janeiro, v. 32, n. 3, p. 105-11, mar. 2010.

CONSELHO FEDERAL DE MEDICINA (CFM) - . Conselhos de medicina se posicionam a favor da autonomia da mulher em caso de interrupção da gestação. Rede dos Conselhos de Medicina. 2013. Disponível em: <http://portal.cfm.org.br/index.php?option=com_content\&view=article\&id=23661 >. Acesso em: 06 nov 2013.

DINIZ, D. Aborto e saúde pública no Brasil. Cadernos de Saúde Pública, Rio de Janeiro, v. 23, n. 9, p, 1992-1993. set. 2007.

DINIZ, D.; MEDEIROS, M. Aborto no Brasil: uma pesquisa domiciliar com técnica de urna. Ciência \& Saúde Coletiva, Rio de Janeiro, v. 15, suppl. 1, p. 959-966. jan./jun. 2010.

DOMINGOS, S. R. F.; MERIGHI, M. A. B. O aborto como causa de mortalidade materna: um pensar para o cuidado de enfermagem. Escola Anna Nery, Rio de Janeiro, v. 14, n. 1, p. 177-181. jan./mar. 2010.

FREIRE, N. Aborto seguro: um direito das mulheres? Ciência e Cultura, São Paulo, v. 64, n. 2, p. 31-32. abr./jun. 2012.

FUSCO, C. L. B.; ANDREONI, S.; SILVA, R. S. Epidemiologia do aborto inseguro em uma população em situação de pobreza Favela Inajar de Souza, São Paulo. Revista Brasileira de Epidemiologia, São Paulo, v. 11, n. 1, p. 78-88. mar. 2008.

GESTEIRA, S. M. A.; DINIZ, N. M. F.; OLIVEIRA, E. M. Assistência à muIher em processo de abortamento provocado: discurso de profissionais de enfermagem. Acta Paulista de Enfermagem, São Paulo, v. 21, n. 3, p. 449-453, jul./set. 2008.

GOLLOP, T. R. Por que despenalizar o aborto? Ciência e Cultura, São Paulo, v. 61, n. 3, p. 4-5. 2009.

HESSINI, L.; SMITH, C. H. O acesso das mulheres ao aborto seguro: estratégias essenciais para alcançarmos as metas do milênio. Rio de Janeiro: Ipas Brasil; 2005.

KLASING, A. Decisão do Supremo Tribunal Federal sobre Aborto é um Passo Positivo avalia Human Rights Watch (HRW). Católicas pelo Direito de Decidir. 2012. Disponível em: <http://catolicasonline.org.br/noticias/conteudo.asp?cod=3412>. Acesso em: 16 abr 2012.

KOTTOW, M. A bioética do início da vida.. In: BRAZ, M.; SCHRAMM, F. R. Bioética e saúde: novos tempos para mulheres e crianças? Rio de Janeiro: Fiocruz, 2005. p. 19-37.

MARTINS, A. L.; MENDONÇA, L. C. Aborto - Mortes Preveníveis e Evitáveis: dossiê. 2005. Rede Feminista de Saúde. Disponível em: <http://abenfo.redesindical.com.br/arqs/manuais/081.pdf>. Acesso em: 20 mar. 2012.

MENEZES, G.; AQUINO, E. M. L. Pesquisa sobre o aborto no Brasil: avanços e desafios para o campo da saúde coletiva. Cadernos de Saúde Pública, Rio de Janeiro, v. 25, suppl 2. p. S193-S204, fev. 2009.

NADER, P. R. A; BLANDINO, V. R. P; MACIE, E. L. N. Características de abortamentos atendidos em uma maternidade pública do Município da Serra - ES. Revista Brasileira de Epidemiologia, São Paulo, v. 10, n. 4. p. 615-624, dez. 2007.

PEREIRA, I. G. Casuística de abortos legais realizados no hospital do Jabaquara entre 1989 e 2007. Saude \& Sociedade, São Paulo, v. 18, supl 1, p. 81, jan./mar. 2009.

PEREIRA, V. N. et al. Abortamento induzido: vivência de mulheres baianas. Saude \& Sociedade, São Paulo, v. 21, n. 4, p. 1056-1062. out./dez. 2012.

ROCHA, M. I. B.; BARBOSA, R. M.(Org.). Aborto no Brasil e países do Cone Sul: panorama da situação e dos estudos acadêmicos. Núcleo de Estudos de População. 2009. Disponível em: <http://www. redesaude.org.br/portal/home/conteudo/biblioteca/biblioteca/ textos-diversos/017.pdf>. Acesso em: 01 abr 2012.

SCAVONE, L. Políticas feministas do aborto. Revista de Estudos Feministas., Florianópolis, v. 16, n. 2, p. 675-80, mai./ago. 2008.

SOUZA, Z. C. S. N. et al. Trajetória de mulheres em situação de aborto provocado no discurso sobre clandestinidade. Acta Paulista de Enfermagem, São Paulo, v. 23, n. 6, p. 732-736, maio/jun. 2010.

SEDGH G. et al. Induced abortion: estimated rates and trends worldwide. Lancet, n. 370, v. 9595, p. 1338-1345. 2007.

SYDOW, E. et al. A história de oito mulheres criminalizadas por aborto. 2011. Disponível em: <http://www.aads.org.br/arquivos/Projeto02.pdf>. Acesso em: 13 maio 2012. 
TEMPORÃO, J. G. Direitos sexuais e reprodutivos das mulheres no Brasil: conquistas recentes e desafios prementes. Ciência e Cultura, São Paulo, v. 64, n. 2, p. 21-23, abr./jun. 2012.

VENTURA, M. Direitos Reprodutivos no Brasil. 3. ed. rev. ampl. Brasília: Fundo de População das Nações Unidas - UNFPA. 2009.

Recebido para publicação em janeiro de 2013

Versão definitiva em dezembro de 2013

Suporte financeiro: não houve

Conflito de interesse: inexistente 